\title{
Genetic characterization of hantaviruses isolated from rodents in the port cities of Heilongjiang, China, in 2014
}

\author{
Suya $\mathrm{CaO}^{1 \dagger}{ }^{\dagger}$, Jian $\mathrm{Ma}^{2+}$, Cheng $\mathrm{Cheng}^{3}$, Wendong $\mathrm{Ju}^{3}$ and Yulong Wang ${ }^{1 *}$
}

\begin{abstract}
Background: Hantavirus is a tripartite negative-sense RNA virus. It can infect humans through contaminated rodent excreta and causes two types of fatal human diseases: hemorrhagic fever with renal syndrome (HFRS) and hantavirus pulmonary syndrome (HPS). China exhibits the highest HFRS occurrence rate in the world, and the Heilongjiang area is one of the most severely infected regions.

Results: To obtain additional insights into the genetic characteristics of hantaviruses in the port cities of the Heilongjiang area in China, a molecular epidemiological investigation of hantaviruses isolated from rodents was performed in 2014. A total of 649 rodents (11 murine species and 1 shrew species) were caught in 12 port cities in Heilongjiang. Among these rodents, the most common species was A. agrarius, and the second-most common was $R$. norvegicus. A viral gene PCR assay revealed the presence of two specific genotypes of hantavirus, referred to as Hantaan virus (HTNV) and Seoul virus (SEOV), and the positive SEOV infection rate was higher than that for HTNV. A genetic analysis based on partial M segment sequences indicated that all of the isolates belonging to SEOV could be assigned to two genetic lineages, whereas the isolate belonging to HTNV could be assigned to only one genetic lineage.
\end{abstract}

Conclusions: These results suggested that HTNV and SEOV are circulating in A. agrarius and $R$. norvegicus in the port cities in the area of Heilongjiang, but SEOV may be the dominant common hantavirus.

Keywords: Hantavirus, SEOV, HTNV, Epidemiology, Heilongjiang

\section{Background}

Hantaviruses, which belong to the Hantavirus genus in the Bunyaviridae family, are tripartite negative-sense RNA viruses. Hantaviruses possess a tripartite negative-sense RNA genome consisting of the following three segments: the large (L) segment encodes a viral RNA-dependent RNA polymerase; the medium-sized (M) segment encodes two viral glycoproteins (GPs, Gn and Gc); and the small (S) segment encodes the viral nucleocapsid protein (NP) [1-5]. The GPs along with the NP determine the virulence and pathogenicity of the hantavirus. Unlike other viruses of the Bunyaviridae family, hantaviruses are not transmitted by arthropods; rather, they infect people though the

\footnotetext{
* Correspondence: wangyl@nefu.edu.com

Suya Cao and Jian Ma are co-first authors.

${ }^{\dagger}$ Equal contributors

${ }^{1}$ Department of Wildlife Medicine, Wild life Resources Faculty, Northeast

Forestry University, Harbin 150040, China

Full list of author information is available at the end of the article
}

urine, saliva and feces excreted by rodent hosts, especially muroids [6, 7]. Hantaviruses only generate transient pathology in rodents, and they do not affect the life span and reproduction of their hosts. In contrast, they can cause two severe clinical manifestations in humans: hemorrhagic fever with renal syndrome (HFRS) in the old world and hantavirus cardiopulmonary syndrome (HPS) in the new world [8-12]. Previous studies have indicated that at least 40 species and 30 genotypes belonging to the hantavirus genus have been isolated worldwide [13].

Etiological studies have shown that HFRS that has spread around the world, resulting in the production of variant hantaviruses. In Asia and Europe, five types of hantaviruses can cause HFRS: Hantaan virus (HTNV), Seoul virus (SEOV), Dobrava virus (DOBV), Saaremaa virus (SAAV), and Puumala virus (PUUV) [14]. In the USA, the Sin Nombre virus (SNV) and the Andes virus (ANDV) are stable viruses that can cause HPS. Most HFRS cases occur in Europe and East Asia (Korea, 
China and the eastern part of Russia) [11, 15]. China is the country that is most seriously affected by hantavirus infection worldwide. Previous investigations have shown that HFRS-infected patients in East Asian countries, including China, Russia and Korea, account for at least $90 \%$ of HFRS patients around the world. At least 100,000 cases of HFRS are reported annually in China, and more than 900 cases are reported in Korea and the eastern part of Russia $[16,17]$. HFRS is caused by different types of hantaviruses in different countries, and phylogenetic analysis suggests that hantaviruses and rodent hosts have coevolved [3]. In China, there are two common types of hantavirus, HTNV and SEOV, which are reportedly carried by $A$ agrarius and $R$. norvegicus, respectively, and some hantaviruses isolated from $R$. norvegicus seemed to be HTNV $[16,18,19]$.

HTNV and SEOV could cause serious public health problems in China, especially in the Heilongjiang area of China. Heilongjiang is located in northeastern China, and it is adjacent to northern Russia and the nearby Jilin area to the south. It was the first area in which the etiological agent of HFRS was isolated in China, [11] and the Heilongjiang area has remained a high-incidence region [20]. Previous studies have shown that SEOV and HTNV are circulating in the Heilongjiang area [21, 22].

The port of Heilongjiang serves as bridge between countries. A single commercial port is used for economic trade, the exchange of technology and culture, tourism, immigration and so on. Given that many anthropozoonoses are transmitted by vectors (material, people and animals), and these vectors might be introduced into China through ports, it is essential to investigate the molecular epidemiology of hantaviruses by monitoring the rodents that are the natural hosts of hantavirus in the port cities of the Heilongjiang area. In this study, 12 port cities have been selected as trapping sites for our hantavirus investigation. We captured 649 rodents and characterized 29 hantaviruses isolated from various rodent species in the port cities. A phylogenetic analysis of the partial $M$ segments indicated that 19 of 29 viruses belonged to SEOV, and 10 of 29 viruses belong to HTNV. Entire M segment of HTNV (TJ strain) which isolated from $R$. norvegicus have been sequenced and compared with the reference HTNVs. The results indicated that the spillover of HTNV has occurred under natural condition in port cities of Heilongjiang area.

\section{Methods}

\section{Rodent collection}

In 2014, rodents were trapped with rat traps or baited cages in the 12 port cities of Luobei, Jiayin, Jiamusi, Dongning, Hulin, Mudanjiang, Mishan, Harbin, Fujin, Tongjiang, Suifenhe, and Raohe (Fig. 1). The trap sites included tussocks, brushwood, residential areas, canals and fields, among other areas. All of the trapped rodents were identified by zootaxy experts, and they were dissected as soon as they were authenticated. Lung tissues were collected from the captured rodents and transported to the HEILONGJIANG ENTRY-EXIT INSPECTION AND QUARANTINE BUREAU at $-80{ }^{\circ} \mathrm{C}$ and stored in a liquid nitrogen tank until further processing. All procedures used in this study were approved by the Institutional Animal Care and Use Committee of Heilongjiang International Travel Healthcare Center (Harbin, China) (XD-25; 12 April 2014).

\section{RNA extraction and RT-PCR}

The RNAprep Pure Tissue Kit (TIANGEN, Beijing, China) was used to extract total RNA from lung tissues, after the lung tissues were ground into a homogeneous mixture with a Tissue Lyser (Qiagen, Hilton, Germany). Purified total RNA was reverse-transcribed using the Superscript First-Strand Synthesis System (Invitrogen, Beijing, China) and random primers (Invitrogen, Beijing, China) to obtain cDNA. The HTNV and SEOV genotypes were amplified via nested PCR. The initial round of PCR product amplification employed the primer pairs HTm1F (5'-AAA GTA GGT GTT AYA TCY TTA CAA TGT GG-3') and HTm1R (5'-GTA CAT CCT GTR CCT ACC CC-3'), and the second round of PCR production used the primer pairs HTm2F ( $5^{\prime}$-GAA TCG ATA CTG TGG GCT GCA AGT GC-3')/HTm2R (5'GGA TTA GAA CCC CAG CTC GTC TC-3') and SEm2F (5'-GTG GAC TCT TCT TCT CAT TAT T-3')/ SEm2R ( $5^{\prime}$-TGG GCA ATC TGG GGG GTT GCA TG$\left.3^{\prime}\right)$. The initial round of PCR cycling consisted of an initial denaturation at $95^{\circ} \mathrm{C}$ for $5 \mathrm{~min}$, followed by 35 cycles of denaturation at $94{ }^{\circ} \mathrm{C}$ for $30 \mathrm{~s}$, annealing at $52{ }^{\circ} \mathrm{C}$ for $30 \mathrm{~s}$, and elongation at $72{ }^{\circ} \mathrm{C}$ for $30 \mathrm{~s}$, with a final extension at $72{ }^{\circ} \mathrm{C}$ for $10 \mathrm{~min}$. The second round of PCR cycling consisted of an initial denaturation at $95{ }^{\circ} \mathrm{C}$ for 5 min, followed by 30 cycles of denaturation at $94{ }^{\circ} \mathrm{C}$ for $30 \mathrm{~s}$, annealing at $55{ }^{\circ} \mathrm{C}$ for $30 \mathrm{~s}$, and elongation at $72{ }^{\circ} \mathrm{C}$ for $30 \mathrm{~s}$, with a final extension at $72{ }^{\circ} \mathrm{C}$ for $10 \mathrm{~min}$. The amplified products were approximately $330 \mathrm{bps}$.

For avoiding possible false positive results caused by RT-PCR assays, a commercial hantavirus detection kit (Hantavirus qPCR assay kit, Huiruibio, China) was also used to confirm the positive results determined by RT-PCR.

The whole $M$ gene of HTNV isolate (TJ) was further amplified by RT-PCR method as following: The $5^{\prime}$ fragement of $\mathrm{M}$ gene was amplified by the primer pairs as : HM1F (5' - CAA CAT TAT ATA TGA TTG TAC CGA T -3')/HM1R (5' - TGA ACC TGT GAG TTA CCT GGC ATA $\left.C-3^{\prime}\right)$, and the $3^{\prime}$ fragement of $M$ gene was amplified by the primer pairs as : HM2F ( $5^{\prime}$ - AGA TGT TAT ATC 


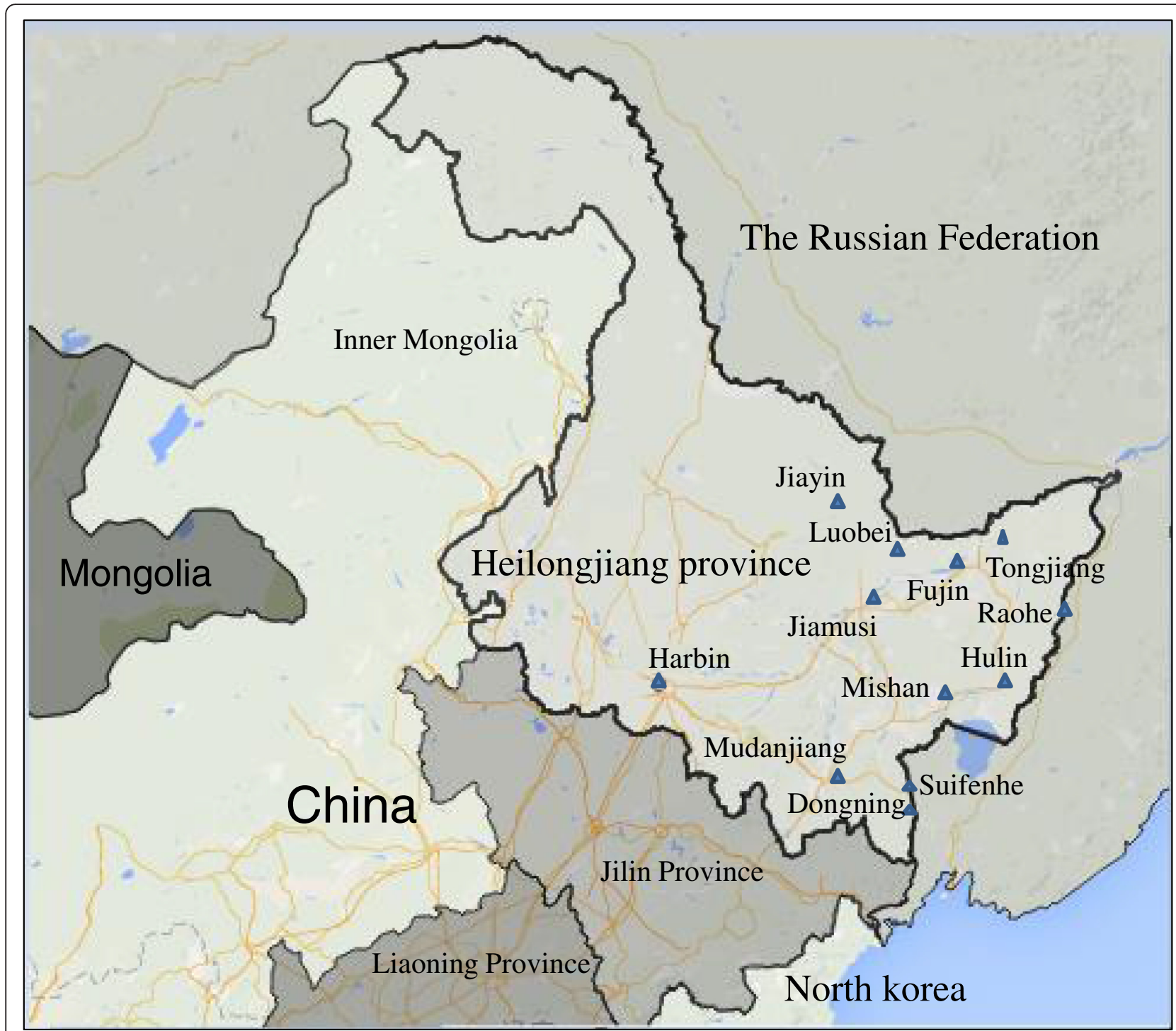

Fig. 1 Map showing the trapping sites for rodents in the Heilongjiang area, China. Almost all of the port cities are located along the border with Russia, except for Harbin and Jiamusi. 48 rodents were captured in Luobei, 79 in Jiayin, 60 in Jiamusi, 22 in Dongning, 36 in Hulin, 27 in Mudanjiang, 102 in Mishan, 95 in Harbin, 29 in Fujin, 60 in Tongjiang, 22 in Suifenhe, and 69 in Raohe

TTT ACA ATG TGG G -3')/HM2R (5'- CAC TCT CTG CAC CAT AAC AGA TAG C -3'). The PCR cycling consisted of an initial denaturation at $95{ }^{\circ} \mathrm{C}$ for $5 \mathrm{~min}$, followed by 35 cycles of denaturation at $94^{\circ} \mathrm{C}$ for $30 \mathrm{~s}$, annealing at $55^{\circ} \mathrm{C}$ for $30 \mathrm{~s}$, and elongation at $72{ }^{\circ} \mathrm{C}$ for $90 \mathrm{~s}$, with a final extension at $72{ }^{\circ} \mathrm{C}$ for $10 \mathrm{~min}$. The sequence of entire $\mathrm{M}$ gene with approximately 1500 bps was obtained by assembling the above two fragements sequences by using DNAStar software.

\section{Phylogenetic analysis of $M$ gene sequences}

The PCR products were purified with the EZNA TM Gel Extraction Kit (OMEGA, USA) according to the manufacturer's instructions and sequenced with the same primers used for PCR amplification. The nucleic acid sequences of the hantaviruses and those downloaded from GenBank were edited and analyzed with the DNASTAR program (DNASTAR, Madison, WI, USA). The identities of the isolated and downloaded hantavirus sequence were also calculated with the DNASTAR program.

The Seqman program was used to edit the nucleic acid sequences. The MEGA 4.0 program was employed to generate a viral phylogenetic tree via the neighborjoining (N J) method. The alignment program of DNAStar software and Gendoc software were used to complete the alignment analyses of amino acid sequence of $M$ segment 
Table 1 Detection of hantavirus in rodent species captured at trap sites in various locations

\begin{tabular}{|c|c|c|c|c|c|c|c|c|c|c|c|c|c|c|c|c|c|c|c|c|c|c|c|c|}
\hline \multirow{3}{*}{$\begin{array}{l}\text { Location } \\
\text { Luobei }\end{array}$} & \multicolumn{24}{|c|}{ Species } \\
\hline & \multicolumn{2}{|c|}{ A. agrarius } & \multicolumn{2}{|c|}{ R. norvegicus } & \multicolumn{2}{|c|}{$\begin{array}{l}\text { Clethrionomys rufocanus } \\
\text { Sundevall }\end{array}$} & \multicolumn{2}{|c|}{ A. peninsulae } & \multicolumn{2}{|c|}{$\begin{array}{l}\text { Clethrionomys } \\
\text { rutilus Pallas }\end{array}$} & \multicolumn{2}{|c|}{ Mus musculus } & \multicolumn{2}{|c|}{$\begin{array}{l}\text { Microtus fortis } \\
\text { Buchner }\end{array}$} & \multicolumn{2}{|c|}{ R. rattus } & \multicolumn{2}{|c|}{ E. sibiricus } & \multicolumn{2}{|c|}{ C. triton } & \multicolumn{2}{|c|}{ S. dauricus } & \multicolumn{2}{|c|}{$\begin{array}{l}\text { Sorex araneus } \\
\text { Linnaeus }\end{array}$} \\
\hline & $0 / 5^{(a)}$ & $0^{(b)}$ & $0 / 3$ & 0 & -(c) & - & $0 / 2$ & 0 & $0 / 11$ & 0 & - & - & $0 / 25$ & 0 & - & - & $0 / 2$ & 0 & - & - & - & - & - & - \\
\hline Jiayin & $1 / 43$ & 2.3 & $0 / 14$ & 0 & $0 / 5$ & 0 & - & - & $0 / 1$ & 0 & $0 / 5$ & 0 & $0 / 2$ & 0 & $0 / 1$ & 0 & $0 / 6$ & 0 & $0 / 2$ & 0 & - & - & - & - \\
\hline Jiamusi & $0 / 15$ & 0 & $4 / 43$ & 9.3 & - & - & - & - & - & - & $0 / 1$ & 0 & - & - & - & - & - & - & - & - & - & - & $0 / 1$ & 0 \\
\hline Dongning & $0 / 5$ & 0 & $5 / 14$ & 35.7 & - & - & - & - & - & - & - & - & - & - & - & - & $0 / 3$ & 0 & - & - & - & - & - & - \\
\hline Hulin & $1 / 21$ & 4.8 & $0 / 4$ & 0 & $0 / 7$ & 0 & $0 / 1$ & 0 & $0 / 3$ & 0 & - & - & - & - & - & - & - & - & - & - & - & - & - & - \\
\hline Mudanjiang & $0 / 21$ & 0 & $2 / 6$ & 33.3 & - & - & - & - & - & - & - & - & - & - & - & - & - & - & - & - & - & - & - & - \\
\hline Mishan & $1 / 51$ & 1.9 & $0 / 25$ & 0 & $0 / 3$ & 0 & $0 / 17$ & 0 & - & - & $0 / 1$ & 0 & - & - & - & - & $0 / 2$ & 0 & $0 / 3$ & 0 & - & - & - & - \\
\hline Harbin & $4 / 36$ & 11 & $0 / 18$ & 0 & - & - & - & - & - & - & - & - & - & - & $0 / 2$ & 0 & - & - & $0 / 36$ & 0 & $0 / 3$ & 0 & - & - \\
\hline Fujin & $1 / 11$ & 9.1 & $0 / 15$ & 0 & - & - & - & - & - & - & - & - & $0 / 3$ & 0 & - & - & - & - & - & - & - & - & - & - \\
\hline Tongjiang & $3 / 46$ & 6.5 & $1 / 11$ & 9.1 & - & - & - & - & - & - & - & - & $0 / 1$ & 0 & - & - & - & - & - & - & - & - & $0 / 2$ & 0 \\
\hline Suifenhe & $0 / 5$ & 0 & $0 / 5$ & 0 & - & - & $0 / 7$ & 0 & - & - & - & - & - & - & - & - & $0 / 1$ & 0 & $0 / 3$ & 0 & - & - & $0 / 1$ & 0 \\
\hline Raohe & $3 / 23$ & 13 & $3 / 22$ & 13.6 & - & - & $0 / 5$ & 0 & $0 / 5$ & 0 & $0 / 2$ & 0 & $0 / 12$ & 0 & - & - & - & - & - & - & - & - & - & - \\
\hline Total & $14 / 282$ & 4.9 & $15 / 180$ & 8.3 & $0 / 15$ & 0 & $0 / 32$ & 0 & $0 / 20$ & 0 & $0 / 9$ & 0 & $0 / 43$ & 0 & $0 / 3$ & 0 & $0 / 14$ & 0 & $0 / 44$ & 0 & $0 / 3$ & 0 & $0 / 4$ & 0 \\
\hline
\end{tabular}

(a) Number of positive samples/Number of tested samples

(b) Positive rate (\%)

${ }^{(c)}$ No Samples 
Table 2 The information of the Hantavirus islalated in this Study

\begin{tabular}{|c|c|c|c|}
\hline Genotype & Isolate & Geographic Location & Accession No. \\
\hline HTNV & CJAp93 & Jilin & EF208930 \\
\hline HTNV & CGHu1 & Guizhou & EU092222 \\
\hline HTNV & Lee & South Korea & D00377 \\
\hline HTNV & $76-118$ & South Korea & Y00386 \\
\hline HTNV & LR1 & China & AF288293 \\
\hline HTNV & S85-46 & China & AF288658 \\
\hline HTNV & 84FLi & Sanxi & AF366569 \\
\hline HTNV & SN7 & China & AF288656 \\
\hline HTNV & N8 & - & EF077656 \\
\hline HTNV & $\mathrm{Z10}$ & Zhejiang & NC_006437 \\
\hline HTNV & ZLS6-11 & Zhejiang & FJ753397 \\
\hline HTNV & A6 & China & AF288645 \\
\hline HTNV & HV114 & Hubei & L08753 \\
\hline HTNV & h5 & Helongjiang & L08753 \\
\hline HTNV & a16 & Sanxi & AF288645 \\
\hline HTNV & AH09 & China & AF285265 \\
\hline HTNV & jilinap06 & Jilin & EF371454 \\
\hline HTNV & Q32 & Guizhou & DQ371905 \\
\hline HTNV & CGRni1 & Guizhou & EU363815 \\
\hline HTNV & TJJ16 & Tianjin & EU074672 \\
\hline HTNV & CGAa4MP9 & Guizhou & EF990929 \\
\hline HTNV & CGAa1015 & Guizhou & EF990926 \\
\hline HTNV & NC167 & Anhui & DQ989237 \\
\hline HTNV & Bao14 & Helongjiang & AB127995 \\
\hline HTNV & TJF3 & Tongjiang & KT885159 \\
\hline HTNV & TJF2 & Tongjiang & KT885160 \\
\hline HTNV & TJF1 & Tongjiang & KT885161 \\
\hline HTNV & $\mathrm{HRH} 14$ & Raohe & KT885162 \\
\hline HTNV & $\mathrm{HRH} 13$ & Raohe & KT885163 \\
\hline HTNV & HMS1 & Mishan & KT885164 \\
\hline HTNV & HMDJ6 & Mudanjiang & KT885165 \\
\hline HTNV & HJY10 & Jiayin & KT885166 \\
\hline HTNV & HJI14 & Harbin & KT885167 \\
\hline HTNV & HHL11 & Hulin & KT885168 \\
\hline SEOV & hebei4 & Hebei & AB027089 \\
\hline SEOV & $\mathrm{Z37}$ & Zhejiang & AF190119 \\
\hline SEOV & ZT71 & Zhejiang & EF117248 \\
\hline SEOV & Sapporo & Sapporo & M34882 \\
\hline SEOV & 80-39 & South Korea & S47716 \\
\hline SEOV & hubei-1 & Hubei & S72343 \\
\hline SEOV & Tchoupitoulas & - & U00473 \\
\hline SEOV & Vietnam5CSG & Vietnam & AB618130 \\
\hline SEOV & guang199 & - & AB027086 \\
\hline SEOV & Houston & UK & U00465 \\
\hline
\end{tabular}

Table 2 The information of the Hantavirus islalated in this Study (Continued)

\begin{tabular}{|c|c|c|c|}
\hline SEOV & HN71-L & Hainan & AB027084 \\
\hline SEOV & K24-V2 & - & AF288654 \\
\hline SEOV & L99 & Jiangxi & AF288298 \\
\hline SEOV & HB55 & Henan & AF035832 \\
\hline SEOV & R22 & Henan & AF035834 \\
\hline SEOV & Brazil & Brazil & U00460 \\
\hline SEOV & humber & UK & JX879768 \\
\hline SEOV & |R461 & UK & AF458104 \\
\hline SEOV & Gou3 & zhejiang & AF145977 \\
\hline SEOV & SDN2 & Dongning & KT885169 \\
\hline SEOV & SDN8 & Dongning & KT885170 \\
\hline SEOV & SDN10 & Dongning & KT885171 \\
\hline SEOV & SDN12 & Dongning & KT885172 \\
\hline SEOV & SDN13 & Dongning & KT885173 \\
\hline SEOV & SDN19 & Dongning & KT885174 \\
\hline SEOV & SJC12 & Harbin & KT885175 \\
\hline SEOV & SJC2O & Harbin & KT885176 \\
\hline SEOV & SJI1 & Harbin & KT885177 \\
\hline SEOV & SJMS16 & Jiamusi & KT885178 \\
\hline SEOV & SJMS19 & Jiamusi & KT885179 \\
\hline SEOV & SJMS21 & Jiamusi & KT885180 \\
\hline SEOV & SJMS30 & Jiamusi & KT885181 \\
\hline SEOV & SMDJ24 & Mudanjiang & KT885182 \\
\hline SEOV & $\mathrm{SRH} 17$ & Raohe & KT885183 \\
\hline SEOV & SRH19 & Raohe & KT885184 \\
\hline SEOV & $\mathrm{SRH} 27$ & Raohe & KT885185 \\
\hline SEOV & SRHA1 & Raohe & KT885186 \\
\hline SEOV & TJF11 & Tongjiang & KT885187 \\
\hline
\end{tabular}

\section{Results \\ Descriptions of the sampled rodents}

In 2014, 649 rodents were captured from the 12 port cities in the Heilongjiang area of China. The rodents included 282 specimens of $A$. agrarius, $180 R$. norvegicus, 15 Clethrionomys rufocanus Sundevall, 32 A. peninsulae, 20 Clethrionomys rutilus Pallas, 9 Mus musculus, 43 Microtus fortis Buchner, 3 R. rattus, 14 E. sibiricus, 44 C. triton, $3 S$. dauricus, and 4 Sorex araneus Linnaeus. The Heilongjiang area harbors a diversity of species, with $A$. agrarius and $R$. norvegicus representing the dominant species. Nested PCR targeting partial $\mathrm{M}$ segment sequences could be applied to screen the infected rodents in all samples. The results showed that the infection rate of $A$. agrarius was $4.9 \%$, and the infection rate of $R$. norvegicus was $8.3 \%$ (Table 1 ). 


\section{Genetic diversity of SEOV isolates}

Phylogenetic tree was constructed with the partial $M$ segment sequences of the viruses (Fig. 2). In the phylogenetic tree analyses of the SEOV isolates, the calculations showed that all of isolates formed six lineages. Lineages 1 to 4 were quite closely related to one another. All of the isolates in lineages 1, 2, and 3 came from China, while the viruses in lineage 4 were isolated from China and neighboring countries (Japan, Korea, Singapore and Vietnam) as well as the United
States. In lineage 4, the isolates came from Jiamusi, Mudanjiang, Harbin and Raohe. The isolates show large sequence distances from strains Z37 and CP211, which were isolated from Zhejiang and Beijing. Lineage 3 consisted of the viruses isolated from Dongning and Raohe, and their virus sequences were very similar. All of the isolates were closely related to the Vietnam5CSG strain previously isolated from small mammals in Vietnam, which is far from the Heilongjiang area. Within lineage 1, strain L99 was

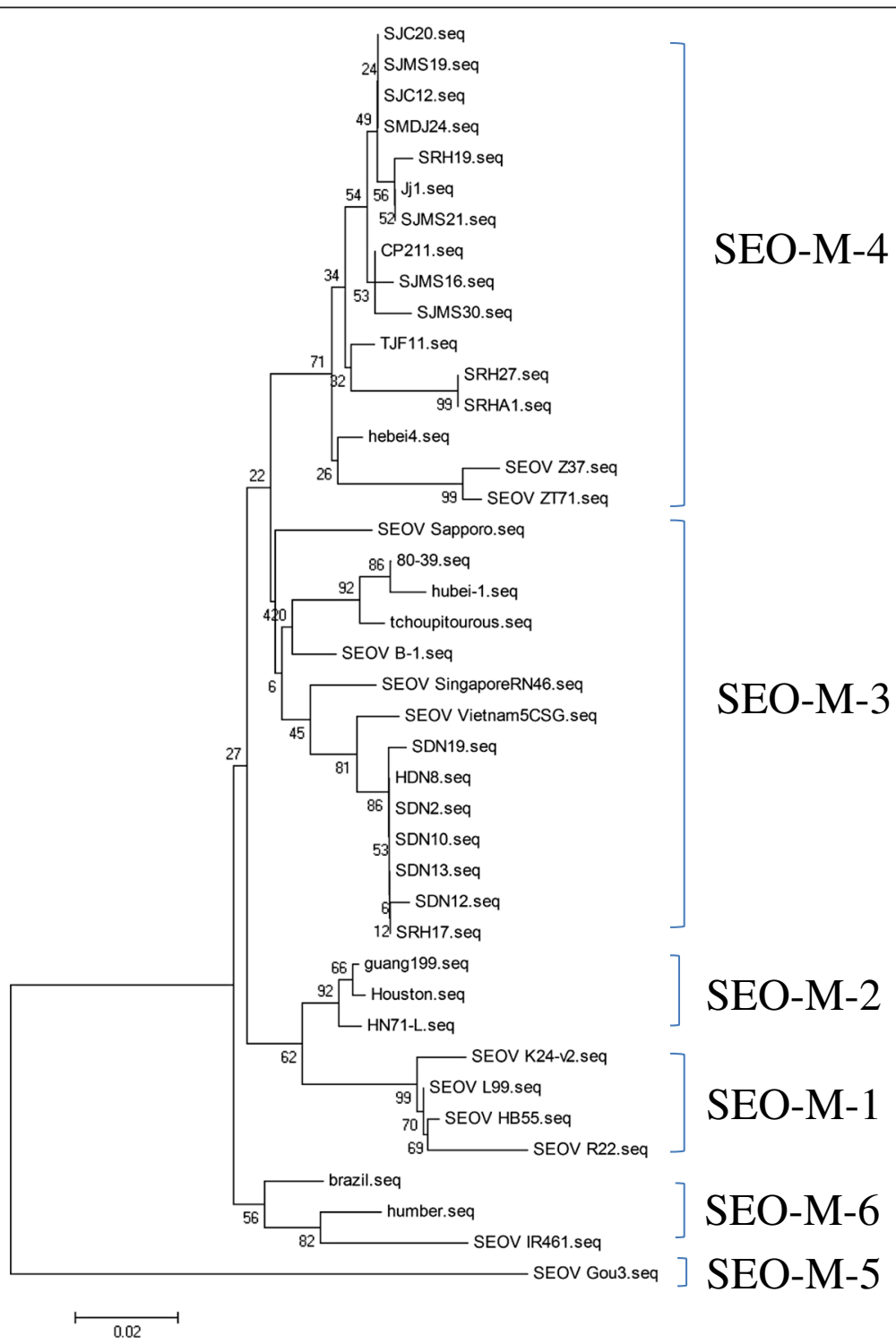

Fig. 2 Phylogenetic tree of Seoul virus isolates based on the partial sequences of M segments. The tree was constructed by the neighbour-joining method (NJ) of Mega software. The HTNVs isolated from R. norvegicus or A. agrarius that were trapped in Harbin were designated SJC20, ji1 and SJC12; those iaolated from Jiamusi, SJMS19, SJMS21, SJMS16, and SJMS30; those isolated fromSuifenhe, SRH19, SRH27, SRH17 and SRHA1; that isolated from Mudanjiang, SMDJ24; that iaolated from Tongjiang, TJF11; and those isolated from Dongning, HDN8, SDN2, SDN10, SDN12 and SDN13. The GenBank accession numbers of the viruses isolated in this study and the reference HTNV stains were listed in Table 2 in detailedly 
isolated from the Jiangxi area, while strain K24-v2 came from the Zhejiang area, and these two areas share borders. The district from which strains R22 and HB55 were isolated, in the Henan area, is located far from the Zhejiang area. Lineage 5 consisted of Gou3, which was isolated from the Zhejiang area, and it appeared to be distinct from the other SEO viruses. Lineage 6 consisted of UK viruses, with the exception of one Brazil strain.

\section{Genetic diversity of HTNV}

The genetic diversity of the HTN isolates was lower than that of the SEO isolates based on the partial M segment sequences. The analysis of the obtained HTNV phylogenetic tree revealed nine lineages from all of the isolated genes (Fig. 3). The partial M segment sequences of HTNV that were isolated in this study belonged to only one lineage, lineage 6 . This lineage has been designated the Far East (FE) lineage,

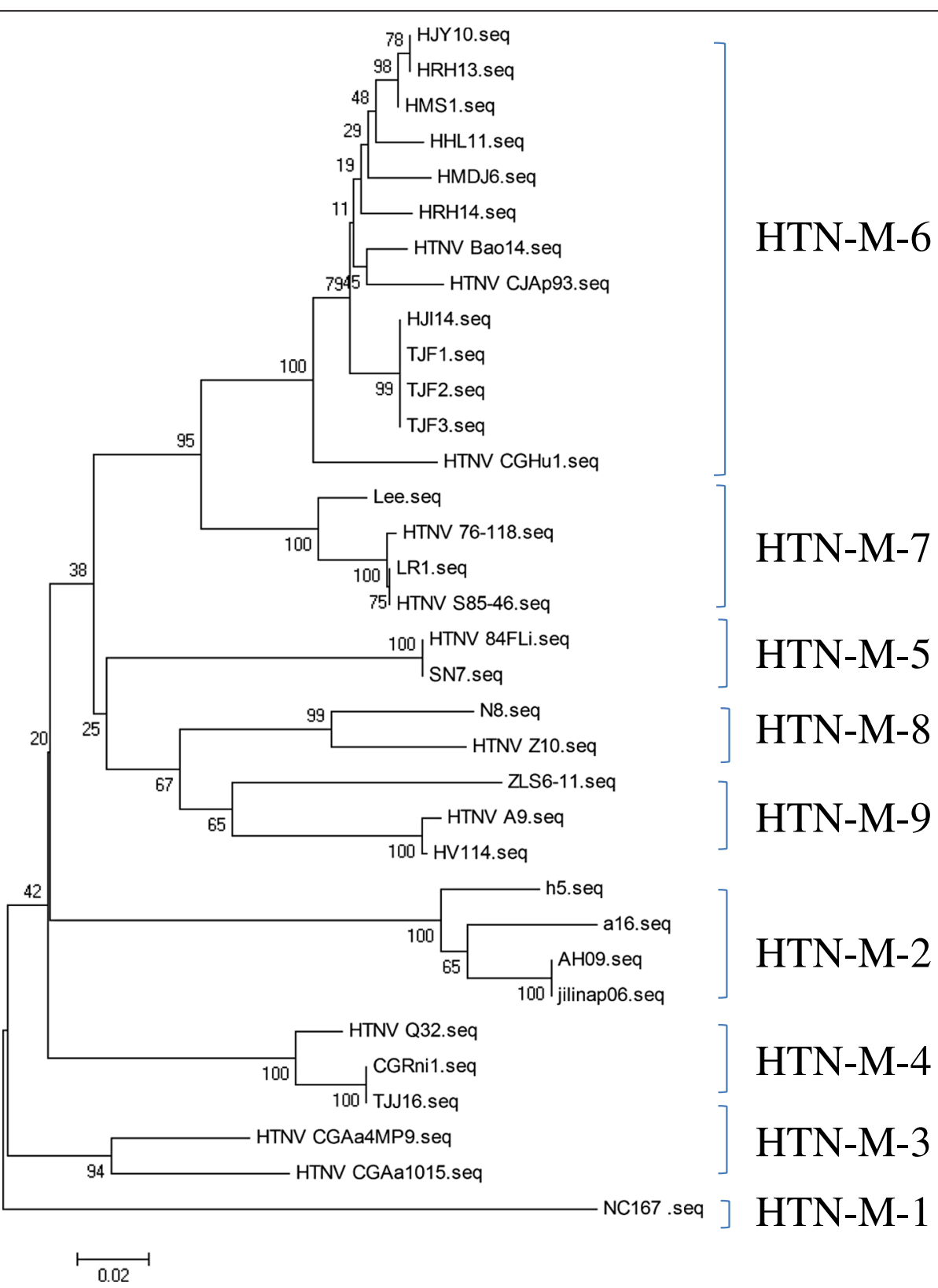

Fig. 3 Phylogenetic tree (NJ) of hantaviruses based on partial M segment sequences of HTNVs from China. The HTNV that isolated from R. norvegicus or A. agrarius that were trapped in Harbin was designated HJI14; those isolated from Tongjiang, TJF1, TJF2 and TJF3; that isolated from Hulin, HHL11; that isolated from Mishan, HMS1; that isolated from Jiayin, HJY10; that isolated from Mudanjiang, HMDJ6; and those isolated from Raohe were designated HRH14 and HRH13. The GenBank accession numbers of the viruses isolated in this study and the referencial SEOV stains were showed in Table 2 in detailedly 
which was identified in patients with serious HFRS. The viruses isolated from the port cities (Jiayin, Raohe, Mishan, Hulin, Mudanjiang and Harbin) in the Heilongjiang area appeared to be very closely related to one another. The Bao14 strain showed a similar sequence to the viruses isolated from the Heilongjiang area and the CJAp93 strain isolated from the Jilin area, which adjoins Heilongjiang. Some of the partial $M$ segment sequences of the isolates from port cities were also closely related to HTNV strains that were isolated far from Heilongjiang, such as the CGHu1 strain originating from the Guizhou area. Lineage 7 consisted of several Korean viruses and shared a common evolutionary source with lineage 6 . Lineage 1 consisted of the novel Hantaan virus type NC167, which was isolated from Anhui. It forms a separate branch in the phylogenetic tree.

\section{Phylogenetic analysis of HTN, SEO and prototype hantaviruses}

To understand more about the HTNV and SEOV genetic variants circulating in rodent hosts in the port cities of the Heilongjiang area, we employed 19 partial M segment sequences of SEOV (KT885169KY885187) and 10 partial $M$ segment sequences of HTNV (KT885159-KT885168) to construct a phylogenetic tree with the reference sequences Hantaan 76-118 and Seoul 80-39 (Fig. 4). The phylogenetic analysis showed that the mutation rates of HTNV isolates were higher than the mutation rates of SEOV isolates, based on the reference hantavirus sequences.

\section{Comparison of amino acid sequences of $M$ segment among HTNVs}

The nucleotide sequence for $\mathrm{M}$ segment of $\mathrm{TJ}$ strain which isolated from $R$. norvegicus is $3408 \mathrm{nt}$, and a 1135 amino acid sequence could be translated by the nucleotide sequence. The alignment result in Fig. 5 showed that there was no deletion or insertion found in the deduced amino acid sequence based on $M$ gene sequence of $\mathrm{TJ}$ strain. The identity of the deduced amino acid sequence between TJ strain and other HTNVs (Bao14, 84Li, N8 and Q32 strain) were more than $95 \%$. Among all the HTNVs, TJ strain showed a highest identity with Bao 14 strain (99.2\%), which was isolated from Heilongjiang too. The previous studies indicated that Five N- glycosylation sites in $\mathrm{Gn}$ (position 134, 235, 347, 399 and 609) and one $\mathrm{N}$ - glycosylation sites in Gc (position 928) were related with the function of $M$ gene coding proteins [23]. However, all of the $\mathrm{N}$ - glycosylation sites were conserved among these different HTNVs (Fig. 5).

\section{Discussion}

The Heilongjiang area is the most seriously affected endemic area of HFRS in China [13]. To gain a better understanding of the genetic characteristics of the hantaviruses present in the port cities in the Heilongjiang area, we collected 649 rodent specimens, and we detected hantaviruses in $A$. agrarius and $R$. norvegicus. The primary rodent hosts in the Heilongjiang area were $A$. agrarius and $R$. norvegicus for all of 2014. Among all of the evaluated rodents, $4.47 \%$ were positive for hantavirus infection. In addition, we analyzed the genetic evolution of hantaviruses based on all of the positive isolates obtained during this study.

The rodent hosts in a specific area and the epidemic genotypes of hantaviruses exhibit a close relationship to epidemics of HFRS. This study showed that two hantaviruses (HTNV and SEOV) are circulating in the Heilongjiang frontier area of northeastern China at present. The epidemiological investigation showed that $A$. agrarius and $R$. norvegicus are the dominant rodent species and carriers of hantavirus in the suburban district and residential areas of the port cities in the Heilongjiang area (Table 1). Although the number of $R$. norvegicus specimens captured in this study was smaller than the number of $A$. agrarius, the $R$. norvegicus infection rate was higher than that of $A$. agrarius. $R$. norvegicus has become an advantageous rodent host for hantavirus, and the SEOV genotype carried by $R$. norvegicus has become the primary genotype of the virus. These results showed that HFRS occurring in the Heilongjiang frontier area might be caused primarily by SEOV. However, the possibility that other hantaviruses also play important roles in causing HFRS in this area could not be eliminated. Therefore, further studies will be necessary to determine whether other viruses are present in the Heilongjiang frontier area, and clinical samples will be needed to clarify the true etiological agents of HFRS in these regions.

Molecular epidemiological analysis has indicated that the SEOVs obtained in this study can be divided into six lineages in phylogenetic trees based on partial M segment sequences [24, 25]. Previous studies showed that lineages 1, 3 and 4 were present in northeastern China $[26,27]$. However, we only isolated the viruses belonging to lineages 3 and 4 in the Heilongjiang frontier area in this study. Notably, these two virus lineages are distributed widely in China, especially in northeastern China and the middle and lower reaches of the Yangtze river $[26,28,29]$. Lineage 4 includes strains from Jilin, Zhejiang and Jiangxi, while lineage 3 includes strains from Japan, Vietnam and South Korea. We surmised that hantaviruses have spread around the world along with their primary natural reservoir, harbored by $R$. norvegicus. Moreover, according to Fig. 2, we observed that lineages $1-4$ exhibit a 


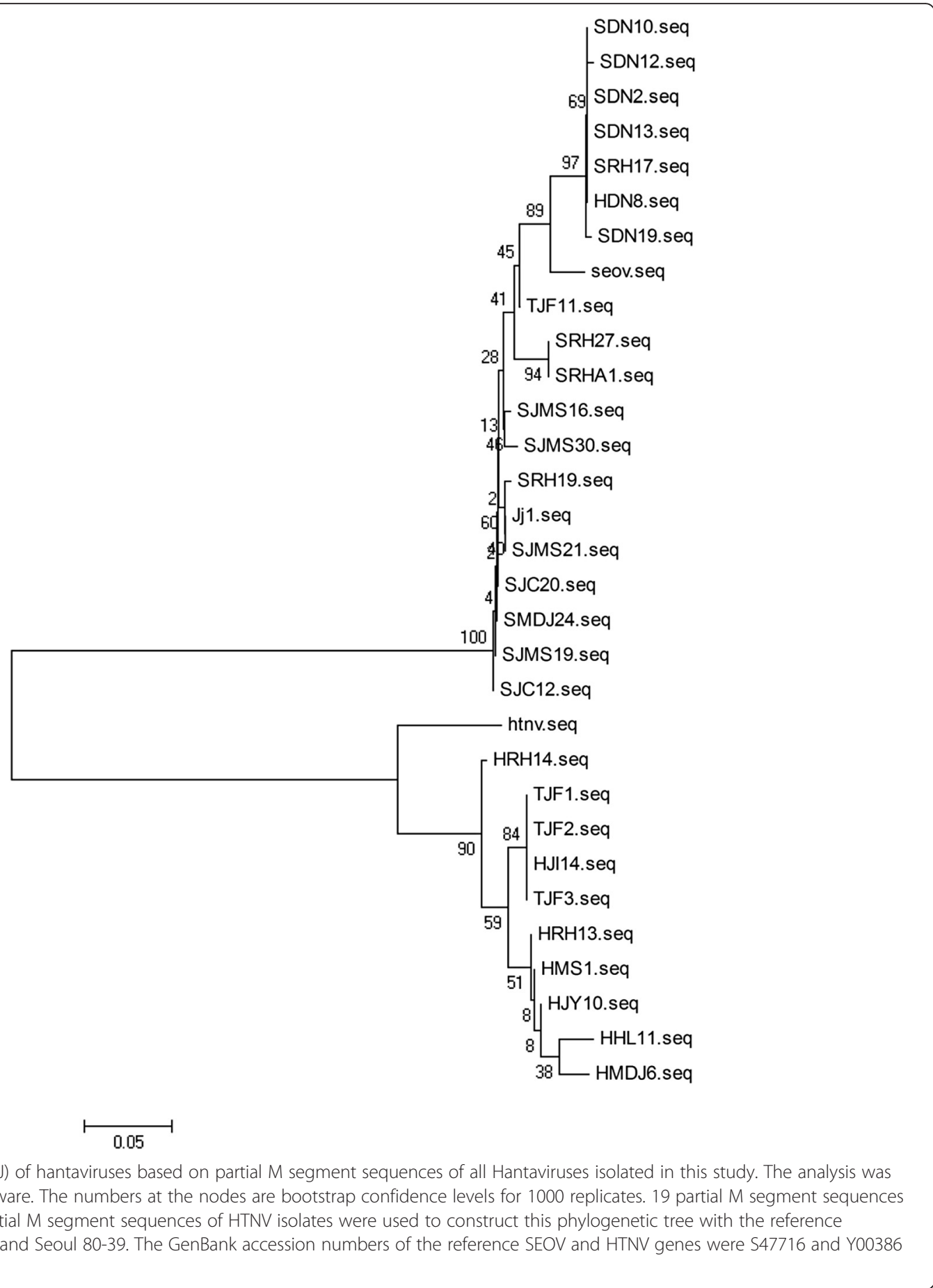

very close evolutionary relationship to lineage 6 . These results indicated that most of the SEOVs isolated from around the world might have evolved from a single ancestor. However, a few variants, such as Gou3, which was isolated from Zhejiang and belongs to lineage 5, show a high degree of variability from most of the other SEOVs, which may suggest the evolution of an ancient hantavirus.
The first time that HTNV was reported was in Korea, and it was carried by A. agrarius [30]. Phylogenetic analysis showed that HTNV can be divided into nine lineages [25]. Previous work demonstrated the presence of lineage 6 in Heilongjiang Province, and lineage 7, which originated from Korea, is found widely throughout China [29, 31]. Several of the 


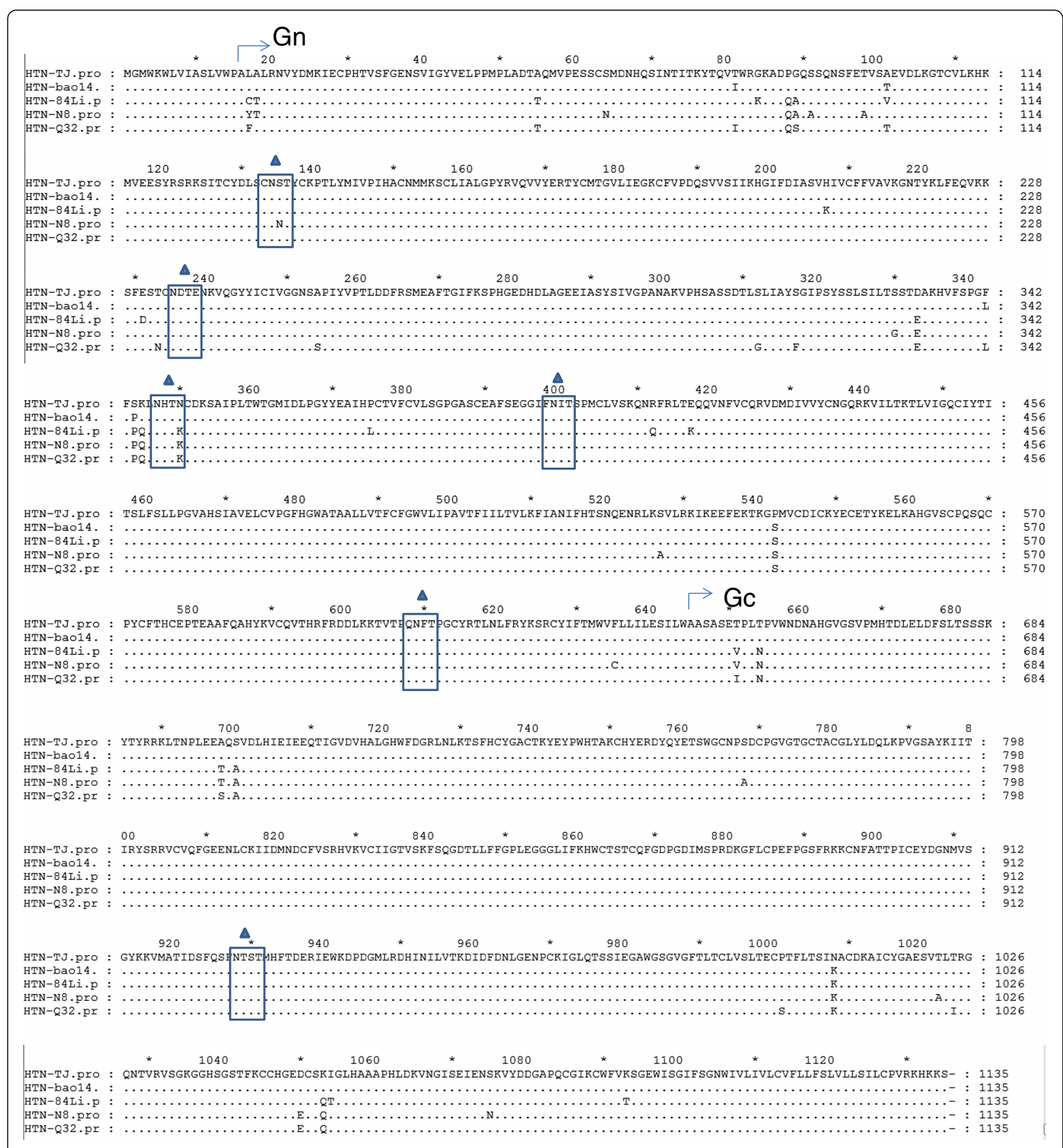

Fig. 5 Multiple alignment of the deduced amino acid sequences based on M gene of hantaviruses isolate TJ and other reference stains. The amino acid differences between $\mathrm{TJ}$ isolate and other strains were shown. The function related $\mathrm{N}$ - glycosylation sites were framed and labled with filled triangles

HTNVs that we detected are similar to the representative strain Bao14. Strains Bao14 and CJAp93, which belong to lineage 6 (lineage $\mathrm{FE}$ ) and were isolated from Heilongjiang and Jilin, respectively, are the main pathogens responsible for HFRS in the northeast region of China. This finding may indicate that this HTNV variant is one of the pathogens associated with
HFRS in northeastern China at present. However, we have not found any isolates that are similar to strain 76-118, which belongs to lineage 7 [31]. Previous studies have indicated that each dominant hantavirus genotype is associated with a specific rodent host, as HTNV is carried by $A$. agrarius, whereas the virus isolated from $R$. norvegicus has been identified as 
SEOV [32]. However, we isolated HTNVs from $R$. norvegicus in this study. This finding may be explained as a spillover infection, though we have not identified spillover of SEOV from $R$. norvegicus to $A$. agrarius. Furthermore, The entire $M$ segment sequence of HTNV isolate (TJ strain) shared high identity with Bao 14 strain (99.2 \%). It indicated that both TJ and Bao14 iaolates may evolve from the same ancestry. And we predicted that the transfer of HTNV infection host might be the approach employed by hantavirus to adapt to environmental change. In addition, all of the isolates (HTNVs and SEOVs) obtained in the present study belong to known lineages, and no new lineage of isolates has emerged in the Heilongjiang area.

\section{Conclusions}

In this study, we found that HTNV and SEOV are circulating in the Heilongjiang frontier area and that SEOVs are the dominant common strains detected in rodent hosts. The HTNV isolates belong to lineage 6, and the SEOV isolates belong to lineages 3 and 4 . All of the lineages are common in the northeast region of China. Although we have not identified a new lineage of hantavirus, regular epidemiological surveillance of local murine colonies is necessary and should be performed intensively.

\section{Abbreviations PUUV: Puumala virus; SAAV: Saaremaa virus; SEOV: Seoul virus; SNV: Sin Nombre virus. \\ Competing interests \\ The authors declare that they have no competing interests.}

ANDV: Andes virus; DOBV: Dobrava virus; HFRS: hemorrhagic fever with renal syndrome; HPS: hantavirus cardiopulmonary syndrome; HTNV: Hantaan virus;

\section{Authors' contributions}

YLW and JM proposed the conception of this study and supervised the project. SYC, CC and WDJ performed the experiments, SYC and JM analyzed the results and wrote this manuscript. All authors read and approved the final manuscript.

\section{Acknowledgments}

This study was supported by the grant from the Fundamental Research Funds for the Central Universities (Grant no. DL13CA04), the grant from the Heilongjiang provincial natural science foundation (Grant no. C201116), and a grant from the General Administration of Quality Supervision, Inspection and Quarantine of the People's Republic of China (AQSIQ) for scientific research subjects (Grant no. 2014IK407).

\section{Author details}

'Department of Wildlife Medicine, Wildlife Resources Faculty, Northeast Forestry University, Harbin 150040, China. ${ }^{2}$ State Key Laboratory of Veterinary Biotechnology, Harbin Veterinary Research Institute, the Chinese Academy of Agriculture Sciences, Harbin 150001, China. ${ }^{3}$ Heilongjiang International Travel Healthcare Center, Harbin 150001, China.

Received: 23 October 2015 Accepted: 23 March 2016

Published online: 02 April 2016

\section{References}

1. Antic D, Lim BU, Kang CY. Nucleotide sequence and coding capacity of the large (L) genomic RNA segment of Seoul 80-39 virus, a member of the hantavirus genus. Virus Res. 1991;19(1):59-65.
2. Hung T, Xia SM, Zhao TX, Zhou JY, Song G, Liao GX, Ye WW, Chu YL, Hang CS. Morphological evidence for identifying the viruses of hemorrhagic fever with renal syndrome as candidate members of the Bunyaviridae family. Brief report. Arch Virol. 1983;78(1-2):137-44.

3. Plyusnin A, Vapalahti O, Vaheri A. Hantaviruses: genome structure, expression and evolution. J Gen Virol. 1996;77(Pt 11):2677-87.

4. Schmaljohn CS, Dalrymple JM. Analysis of Hantaan virus RNA: evidence for a new genus of bunyaviridae. Virology. 1983;131(2):482-91.

5. Luan VD, Yoshimatsu K, Endo R, Taruishi M, Huong VT, Dat DT, Tien PC, Shimizu K, Koma T, Yasuda SP, et al. Studies on hantavirus infection in small mammals captured in southern and central highland area of Vietnam. J Vet Med Sci. 2012;74(9):1155-62.

6. Douron E, Moriniere B, Matheron S, Girard PM, Gonzalez JP, Hirsch F, McCormick JB. HFRS after a wild rodent bite in the Haute-Savoie-and risk of exposure to Hantaan-like virus in a Paris laboratory. Lancet (London, England). 1984;1(8378):676-7.

7. Tsai TF. Hemorrhagic fever with renal syndrome: mode of transmission to humans. Lab Anim Sci. 1987;37(4):428-30.

8. CfDCaP CDC. Update: hantavirus pulmonary syndrome-United States, 1993. MMWR Morb Mortal Wkly Rep. 1993;42(42):816-20

9. Clement J, Heyman P, McKenna P, Colson P, Avsic-Zupanc T. The hantaviruses of Europe: from the bedside to the bench. Emerg Infect Dis. 1997;3(2):205-11.

10. Hughes JM, Peters CJ, Cohen ML, Mahy BW. Hantavirus pulmonary syndrome: an emerging infectious disease. Science (New York, NY). 1993; 262(5135):850-1.

11. Schmaljohn C, Hjelle B. Hantaviruses: a global disease problem. Emerg Infect Dis. 1997;3(2):95-104.

12. Mackow ER, Dalrymple NA, Cimica V, Matthys V, Gorbunova E, Gavrilovskaya I. Hantavirus interferon regulation and virulence determinants. Virus Res. 2014;187:65-71.

13. Jonsson CB, Figueiredo LT, Vapalahti O. A global perspective on hantavirus ecology, epidemiology, and disease. Clin Microbiol Rev. 2010;23(2):412-41.

14. Sane J, Reimerink J, Harms M, Bakker J, Mughini-Gras L, Schimmer B, van Pelt W. Human hantavirus infections in the Netherlands. Emerg Infect Dis. 2014;20(12):2107-10.

15. Vapalahti O, Mustonen J, Lundkvist A, Henttonen H, Plyusnin A, Vaheri A. Hantavirus infections in Europe. Lancet Infect Dis. 2003;3(10):653-61.

16. Song $\mathrm{G}$. Epidemiological progresses of hemorrhagic fever with renal syndrome in China. Chin Med J (Engl). 1999;112(5):472-7.

17. Tkachenko EA, Lee HW. Etiology and epidemiology of hemorrhagic fever with renal syndrome. Kidney Int Suppl. 1991;35:S54-61.

18. Zhang $Y Z$, Xiao DL, Wang $Y$, Wang HX, Sun L, Tao XX, Qu YG. The epidemic characteristics and preventive measures of hemorrhagic fever with syndromes in China. Zhonghua Liu Xing Bing Xue Za Zhi. 2004:25(6):466-9.

19. Zou Y, Hu J, Wang ZX, Wang DM, Yu C, Zhou JZ, Fu ZF, Zhang YZ. Genetic characterization of hantaviruses isolated from Guizhou, China: evidence for spillover and reassortment in nature. J Med Virol. 2008;80(6):1033-41.

20. Li CP, Cui Z, Li SL, Magalhaes RJ, Wang BL, Zhang C, Sun HL, Li CY, Huang $L Y, M a J$, et al. Association between hemorrhagic fever with renal syndrome epidemic and climate factors in Heilongjiang Province, China. Am J Trop Med Hyg. 2013;89(5):1006-12.

21. Chen HX, Qiu FX, Dong BJ, Ji SZ, Li YT, Wang Y, Wang HM, Zuo GF, Tao XX, Gao SY. Epidemiological studies on hemorrhagic fever with renal syndrome in China. J Infect Dis. 1986;154(3):394-8.

22. Chen LF XJ, Liu ZW, Liu YC, Sun CQ, Li JH, et al.: First molecular identifi cation of Seoul hantavirus isolated from Rattus norvegicus in Heilongjiang, China. China Public Health 2001(17):343.

23. Kariwa H, Isegawa Y, Arikawa J, Takashima I, Ueda S, Yamanishi K, Hashimoto N. Comparison of nucleotide sequences of M genome segments among Seoul virus strains isolated from eastern Asia. Virus Res. 1994;33(1):27-38.

24. Cosgriff TM. Mechanisms of disease in Hantavirus infection: pathophysiology of hemorrhagic fever with renal syndrome. Rev Infect Dis. 1991;13(1):97-107.

25. Kanerva M, Mustonen J, Vaheri A. Pathogenesis of puumala and other hantavirus infections. Rev Med Virol. 1998;8(2):67-86.

26. Zhang YZ, Dong X, Li X, Ma C, Xiong HP, Yan GJ, Gao N, Jiang DM, Li MH, Li LP, et al. Seoul virus and hantavirus disease, Shenyang, People's Republic of China. Emerg Infect Dis. 2009;15(2):200-6. 
27. Zhang YZ, Zhang FX, Wang JB, Zhao ZW, Li MH, Chen HX, Zou Y, Plyusnin A. Hantaviruses in rodents and humans, Inner Mongolia Autonomous Region, China. Emerg Infect Dis. 2009;15(6):885-91.

28. Shi X, McCaughey C, Elliott RM. Genetic characterisation of a Hantavirus isolated from a laboratory-acquired infection. J Med Virol. 2003;71 (1):105-9

29. Wang H, Yoshimatsu K, Ebihara H, Ogino M, Araki K, Kariwa H, Wang Z, Luo Z, Li D, Hang C, et al. Genetic diversity of hantaviruses isolated in china and characterization of novel hantaviruses isolated from Niviventer confucianus and Rattus rattus. Virology. 2000;278(2):332-45.

30. Lee HW, Lee PW, Johnson KM. Isolation of the etiologic agent of Korean hemorrhagic fever. 1978. J Infect Dis. 2004;190(9):1711-21.

31. Jiang JF, Zhang WY, Yao K, Wu XM, Zuo SQ, Zhan L, Zhang PH, Cao WC. A new Hantaan-like virus in rodents (Apodemus peninsulae) from Northeastern China. Virus Res. 2007;130(1-2):292-5.

32. Plyusnin A, Morzunov SP. Virus evolution and genetic diversity of hantaviruses and their rodent hosts. Curr Top Microbiol Immunol. 2001;256:47-75.

Submit your next manuscript to BioMed Central and we will help you at every step:

- We accept pre-submission inquiries

- Our selector tool helps you to find the most relevant journal

- We provide round the clock customer support

- Convenient online submission

- Thorough peer review

- Inclusion in PubMed and all major indexing services

- Maximum visibility for your research

Submit your manuscript at www.biomedcentral.com/submit 